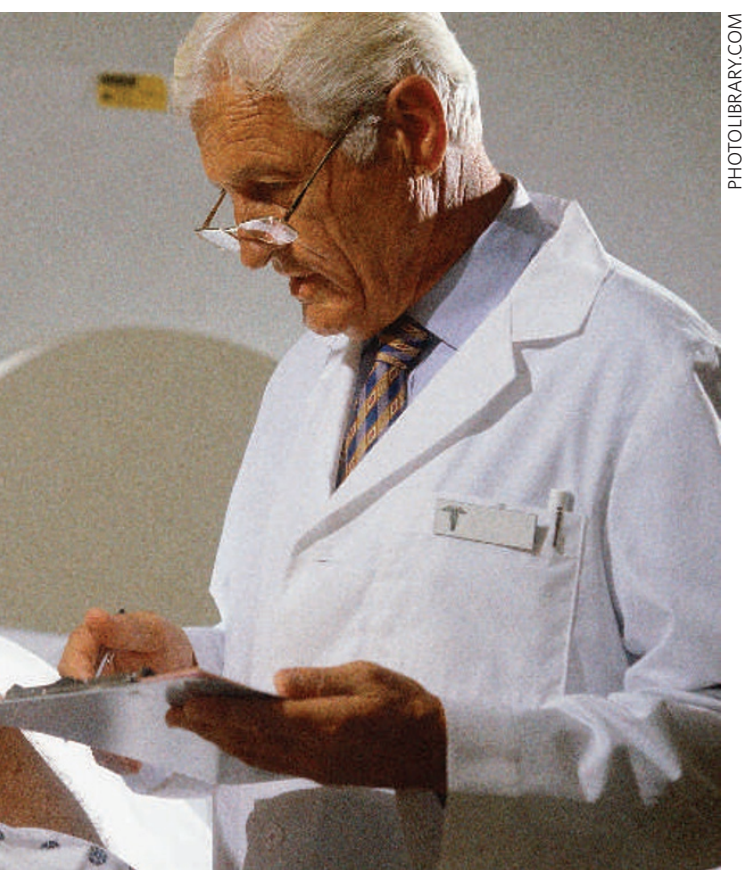

to withdraw it from testing can be clouded by wishful thinking. In biotechnology companies with only one or two drugs in development, the whole future of the company and its employees can hang on the success of a single compound; employees financially and emotionally invested in an experimental drug may ignore warning signs. In larger drug companies, too, those who have spent years working on a compound are obviously keen to see it succeed. "People get quite wedded to their products," Roberts says.

Another way to improve trial success rates, Roberts says, is to identify subgroups of patients in which a drug is more likely to work, using technology such as genetic tests or biomarkers. Some companies are reluctant to do this, fearing that it will reduce the market for which a drug can ultimately be sold. But Roberts has calculated in an economic model that this loss would be offset by money saved from otherwise unsuccessful phase III trials. "In my view it's one of the most powerful ways we could improve the situation," he says.

Such an approach offers a sliver of hope to those in the stroke field. After the poor phase III results, AstraZeneca cancelled the programme and it has no other stroke drugs in development. Few major pharmaceutical companies are pursuing neuroprotectants, although some academic researchers and smaller companies are. But researchers are still hopeful of finding subgroups that respond better to other experimental drugs - perhaps by identifying those best suited to treatment with brain imaging. Ultimately, the field must "deal with this wreckage" from the failure, says Fisher, and move on to new candidates.

\section{IN BRIEF}

GENOMICS GRAB Illumina, the gene-chip maker based in San Diego, says that it will pay $\$ 600$ million to acquire Solexa, a manufacturer of gene-sequencing machines. The merger, expected to be complete by 31 March next year, will create the first company with technologies in large-scale genotyping, gene expression and gene sequencing - the main tools for exploiting information from the human genome. The move caps a year of significant gains for Illumina (see Nature 444, 256-257; 2006), which says it will retain Solexa's current operations in Hayward, California, and Cambridge, UK.

\section{SUPERCONTRACTING The US Defense Advanced Research Projects Agency} (DARPA) says it is granting almost $\$ 500$ million to IBM and Cray to press ahead with the development of supercomputers. The contracts place strong emphasis on making sure that it will be easy to write applications software that will actually make use of computers' vast processing power. DARPA says the computers will deliver performance of more than a petaflop, or $10^{15}$ floating-point operations per second.

MERGER MANIA Mergers and acquisitions of biotechnology companies soared in the second half of 2006, according to a report by Sanford C. Bernstein, an investment research and management firm based in New York. Since July, biotech firms have merged with - or, more frequently, been acquired by - other biotech or drug companies in nine deals worth $\$ 24.3$ billion. That compares with $\$ 15$ billion in similar deals in the whole of 2005 , and $\$ 2.9$ billion in the first half of this calendar year. "We're in record territory in terms of both numbers and value of these mergers," says report author Geoffrey Porges.

\title{
MARKET WATCH
}

EUROPEAN CARBON INDEX

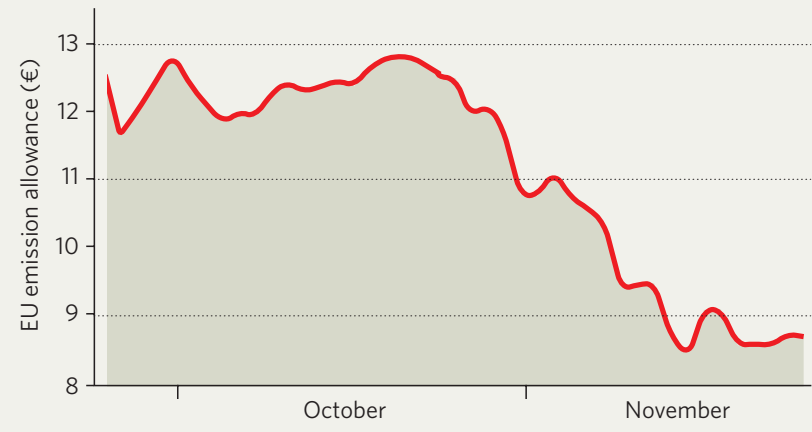

The price of European Union (EU) allowances for carbon dioxide emissions has steadily declined over the past six weeks, reaching an all-year low of less than $€ 8.50$ (US\$11.11) last week.

Even optimists are now having doubts about whether the market will recover again during the rest of the first phase of the EU's emission trading system, which finishes at the end of 2007. Most companies participating in the system own enough allowances for next year, and large energy producers have lost interest in backing the market by buying more allowances than necessary. As a result, analysts say, prices may go further downhill.

"Given the surpluses, the price should in theory approach zero," says Stefan Kleeberg, who watches energy markets for $3 \mathrm{C}$ Climate Change Consulting in Frankfurt, Germany.
The poor outcome of the United Nations' climate summit in Nairobi has not exactly stirred euphoria among emissions traders. Nonetheless, analysts reject the idea that the trading system might collapse altogether. "The books are closed for 2006 and 2007," says Kleeberg. "But questioning the efficiency of the system as such would be wrong." Emissions allowances for the second trading period, from 2008 to 2012, are currently traded at around $€ 17$, meaning that the difference between phase I and phase II prices is at its largest ever. Reports last week that the European Commission will reject Germany's national allocation plan for 2008-12 - effectively demanding tighter caps on Europe's largest emitter - fuelled demand for phase-II allowances at European carbon exchanges. Quirin Schiermeier 